\title{
Perceptual asymmetries and handedness: a neglected link?
}

\author{
Daniele Marzoli $^{1}$ *, Giulia Prete ${ }^{2}$ and Luca Tommasi ${ }^{1}$ \\ ${ }^{1}$ Department of Psychological Sciences, Humanities and Territory, University of Chieti, Chieti, Italy \\ ${ }^{2}$ Department of Neuroscience and Imaging, University of Chieti, Chieti, Italy
}

\section{Edited by:}

Sebastian Ocklenburg, University of

Bergen, Norway

Reviewed by:

Orsola Rosa Salva, University of

Trento, Italy

Jacqueline Angelique De Nooijer,

Erasmus University Rotterdam,

Netherlands

\section{${ }^{*}$ Correspondence:}

Daniele Marzoli, Department of Psychological Sciences, Humanities and Territory, University of Chieti, Via dei Vestini 29, I-66013 Chieti, Italy e-mail:d.marzoli@unich.it
Healthy individuals tend to weigh in more the left than the right side of visual space in a variety of contexts, ranging from pseudoneglect to perceptual asymmetries for faces. Among the common explanations proposed for the attentional and perceptual advantages of the left visual field, a link with the prevalence of right-handedness in humans has never been suggested, although some evidence seems to converge in favor of a bias of spatial attention toward the region most likely coincident with another person's right hand during a face-to-face interaction. Such a bias might imply an increased efficiency in monitoring both communicative and aggressive acts, the right limb being more used than the left in both types of behavior. Although attentional and perceptual asymmetries could be linked to right-handedness at the level of phylogeny because of the evolutionarily advantage of directing attention toward the region where others' dominant hand usually operates, it is also legitimate to question whether, at the ontogenetic level, frequent exposure to righthanded individuals may foster leftward biases. These views are discussed in the light of extant literature, and a number of tests are proposed in order to assess our hypotheses.

Keywords: perceptual and attentional asymmetries, handedness, left face bias, face, body
As largely shown by past research, healthy individuals tend to weigh in more the left than the right side of visual space in a variety of contexts, ranging from pseudoneglect (for a review, see Jewell and McCourt, 2000) to perceptual and attentional asymmetries for faces (e.g., Burt and Perrett, 1997; Hsiao and Cottrell, 2008). Among the common explanations provided for the existence of such attentional and perceptual advantages of the left visual field, including hemispheric asymmetries for processing faces (Bentin et al., 1996; Kanwisher et al., 1997; Yovel et al., 2008; Prete et al., 2013), spatial information (Mesulam, 1981; Corbetta and Shulman, 2002), and social information (Brancucci et al., 2009), a possible functional link between leftward biases and the prevalence of right-handedness in human population has never been proposed, beyond a bulk of correlational studies. In fact, while it is controversial whether the right-hemispheric specialization for face processing drives the leftward bias for faces or vice versa (Dundas et al., 2012b), no one has attempted to relate such a bias to the potential advantage of better monitoring others' dominant hand. In fact, it should be noted that the region of a person's right hand and limb, with respect to an observer facing that person (assuming a face-to-face interaction), falls in the observer's left field of view, so that any leftward bias would drive the focus of attention on the most active side of others' body.

In other words, it could be not by chance that the location in space of others' right hand, from the point of view of the observer, coincides with the well-known leftward bias of spatial attention, usually indicated as pseudoneglect (Bowers and Heilman, 1980; Jewell and McCourt, 2000). This is a natural property of attention whereby the left side of visual space is more relevant than the right side, as witnessed by the more frequent leftward errors made in bisection tasks (e.g., dividing a line or a rod into two halves), or by the fact that judgments on brightness, numerosity, and size are similarly skewed in favor of the left hemispace. A similar advantage for the left side is also observed in face perception, consisting in a preferential reliance upon the features on the left side of an observed face, when one has to make judgments about gender, attractiveness, age, and emotional expression conveyed by that face (Burt and Perrett, 1997). This is also reflected in the higher frequency of eye movements directed to the left side of the face (Butler et al., 2005). Given their biological relevance and their indivisibility from body - and thus from arms - in ecological settings, faces offer the best subject of inquiry to test our hypothesis.

\section{WHICH ARE THE POTENTIAL ADVANTAGES OF LEFTWARD ASYMMETRIES?}

We believe that a bias of spatial attention toward the region most likely coincident with others' right hand might have a deeply rooted justification in the communicative advantage conferred by attending to the limb most frequently used in gesturing, above all by right-handers and during speech (Kimura, 1973a,b; Dalby et al., 1980; Lavergne and Kimura, 1987; Saucier and Elias, 2001). Furthermore, the left-sided attentional bias might ensure a more efficient monitoring of aggressive behavior, the right limb being more used than the left also in violent actions (Coren and Porac, 1977). The other side of the coin is that a reduced monitoring of the right side of space - the space in which falls the dominant hand of encountered left-handed individuals - could contribute to the "surprise effect" at the basis of the left-handers' advantage in fighting and sports (Raymond et al., 1996).

Clearly, this line of argument holds for right-handed subjects in the role of observers, and to some extent one would predict that it should also hold for left-handed observers, at least on the basis of visual experience. For example, Hagemann (2009) found that the directions of tennis strokes performed with the right hand were easier to predict compared to those performed with the left 
hand, regardless of observers' handedness. Similarly, Marzoli et al. (in preparation) observed that, when required to report the perceived orientation (front or back view) of pictures of ambiguous human silhouettes performing one-handed manual actions, both right- and left-handers perceived the figure more frequently in an orientation congruent with a movement performed with the right rather than the left hand. However, one should not forget the possible contribution of motor representations in shaping attentional biases. In fact, the left hemispatial bias for face processing usually observed in right-handers is absent (Jaynes, 1976; Heller and Levy, 1981; Roszkowski and Snelbecker, 1982; Hoptman and Levy, 1988) or weaker (Luh et al., 1994) in left-handers. Moreover, left-handers turn out to be less affected by a leftward pseudoneglect (Brodie and Dunn, 2005; see also the meta-analysis by Jewell and McCourt, 2000). In support of a role of hand-related motor representations, attention has been reported to be biased toward the right and left side of observed bodies, regardless of their spatial orientation, respectively, in right- and left-handers (Gardner and Potts, 2010; see also Zartor et al., 2010). Analogous effects of handedness have been reported by our own group for the imagination of others' actions (Marzoli et al., 2011a,b, in preparation). Noteworthy, these results seem to be in line with our proposal of a link between well-known attentional and perceptual leftward biases and an attentional bias toward the right side of others' body, such biases being affected in similar ways by handedness. However, we point out that viewing perspective seems to interact with motor experience as regards attentional asymmetries toward others' body, yielding a specific pattern of results (Marzoli et al., 2011a): when an actor is imagined as seen from the front, right-handers' attention is biased toward their own dominant hand (that is, toward the left from their own point of view), whereas left-handers' attention is biased toward their own non-dominant hand (that is, toward the left from their own point of view) or not biased at all; when an actor is imagined as seen from the back, both right-handers' and left-handers' attention is biased toward their own dominant hand (that is, toward the left from left-handers' point of view and toward the right from right-handers' point of view). Likewise, handedness does not affect perceptual and attentional asymmetries in the same direction in all tasks: form recognition and dot localization do not elicit any visual field difference between rightand left-handers, whereas letter recognition is performed better in the right visual field by right-handers, but not by left-handers (Bryden, 1973).

\section{DEVELOPMENTAL TREND IN THE LEFT FACE BIAS: IS THERE A ROLE FOR EXPERIENCE?}

In our opinion, the role of experience in the establishment of perceptual asymmetries in face processing deserves in-depth investigation. For example, the direction of reading and writing systems that characterize the various human cultures (left-to-right or right-to-left) has been called into cause as a possible factor modulating the leftward lateral bias for face exploration and attention (Vaid and Singh, 1989; Sakhuja etal., 1996; Heath et al., 2005; Megreya and Havard, 2011). Therefore, we want to highlight how, although attentional and perceptual asymmetries could be linked to right-handedness at the level of phylogeny - because of the evolutionarily adaptive advantage of directing attention toward the region of visual space where others' dominant hand usually operates - it is also legitimate to question whether, at the ontogenetic level, frequent exposure to right-handed individuals may foster leftward biases.

In this regard, it should be stressed that, whereas the leftward bias in face perception is usually observed in children of about 5 years (e.g., Roszkowski and Snelbecker, 1982; Levine and Levy, 1986; Kolb et al., 1992; Failla et al., 2003; Workman et al., 2006; Aljuhanay et al., 2010; Taylor et al., 2012), it is often reported to increase with age and reach an adult-like level by the age of about 10 years (Chiang et al., 2000; Workman et al., 2006; Anes and Short, 2009; Balas and Moulson, 2011; Taylor et al., 2012; Watling and Bourne, 2013; for a review, see Watling et al., 2012). However, the use of different methods seems to provide data in favor of both earlier (e.g., eye tracking; Wheeler, 2010; Liu et al., 2011; Dundas et al., 2012b) and later (e.g., moving window technique; Birmingham et al., 2012) emergence of an appreciable leftward bias in face processing. Similarly, a developmental trend has been shown in studies on the right-hemispheric advantage for face processing (Reynolds and Jeeves, 1978), although it is not always observed, maybe because of procedural differences (Young and Ellis, 1976; Young and Bion, 1980). Further support to our proposal can be drawn from studies showing that a general leftward bias for both upright and inverted human faces, monkey faces, and objects in infancy becomes a specific leftward bias for upright human faces in adulthood (Guo et al., 2009), and that the increase in leftward bias is specific for human faces, which suggests its experiencedependent nature (Balas and Moulson, 2011). A leftward bias for attending human faces was also reported for laboratory-raised rhesus monkeys and domestic dogs (Guo et al., 2009; see Dahl et al., 2013 for congruent findings in chimpanzees). Interestingly, the bias was absent for monkey and dog faces in dogs, and we believe that the prolonged experience with right-handed humans could be a more plausible account for such a specificity compared to other interpretations (e.g., a right-hemispheric specialization for human but not dog faces in both humans and dogs). Although rhesus monkeys showed a leftward bias for both human and monkey faces, given that they were presented only with human and monkey faces but not with dog faces, it cannot be resolved whether such a result was due to their difficulty in differentiating between the two species, to their experience with right-handed monkeys and humans, or to a non-species-specific bias. However, there is some evidence of right-handedness at least in captive rhesus monkeys (Westergaard and Suomi, 1996), as well as in other primates such as chimpanzees, gorillas, and baboons (see Hopkins, 2006; Cochet and Byrne, 2013; Meguerditchian et al., 2013 for reviews). We point out that population-level right-handedness is observed more often in captive rather than wild primates, as well as for communicative gestures rather than non-communicative actions, which has been credited to interaction with humans (Cochet and Byrne, 2013; Meguerditchian et al., 2013). This could suggest a crucial role for social factors also in the emergence of the left face/left visual field bias observed during emotional processing in nonhuman primates (see Lindell, 2013 for a review). On the other hand, findings from animal studies should be considered with caution as regards the origin of the leftward bias for faces, given that several results are inconsistent with a crucial role of interaction with 
humans even in domestic animals. For example, Racca et al. (2012) used emotional faces of both dogs and humans and found a more complex pattern of results compared to those of Guo et al. (2009), dogs showing a left gaze bias for conspecific negative expressions, a right gaze bias for conspecific positive expressions and no bias for conspecific neutral expression, as well as a left gaze bias for human negative and neutral expressions and no bias for human positive expressions. Moreover, sheep exhibit a left visual field advantage for conspecific (Peirce et al., 2000) but not for human faces (Peirce et al., 2001). Domestic chicks with no visual experience of human eyes and gaze also show a left visual field preference for monitoring a human-like dummy mask (Rosa Salva et al., 2007), which shows that even the emergence of leftward biases for human faces can be completely independent from interaction with humans.

The idea that the frequent interaction with right-handed individuals might promote leftward biases is consistent not only with both the experience-expectant and the experience-dependent view of brain development (Greenough et al., 1987), but also with previous studies showing that experience can affect the lateralization of face processing (e.g., infant holding biases; Vervloed et al., 2011; reading habits; Vaid and Singh, 1989; Sakhuja et al., 1996; Heath et al., 2005; Megreya and Havard, 2011). However, the fact that eye tracking studies reveal that a left visual field bias during face observation emerges within 9-11 months (Wheeler, 2010; Liu et al., 2011; Dundas et al., 2012b) and the fact that the leftward bias becomes more specific for upright human faces with increasing age (Guo et al., 2009) indicate that reading habits cannot account for the emergence of the bias. On the other hand, the cumulative experience with right-handed individuals might be responsible for the leftward bias increasing and becoming more selective with age. Moreover, given that the number of interactions with partners other than the primary caregiver increases with time, it should be investigated whether children of left-handed mothers show a shift from a rightward bias to a leftward one over time (in this regard, see Wheeler, 2010, who observed that in children aged 3-6 months with a rightward bias, this decreased with age).

The developmental trend in right-hemispheric specialization for faces has been credited to a parallel increase in righthemispheric specialization for configural processing (Anes and Short, 2009). However, if the leftward bias for face processing is linked to configural processing, it should be noted that body configural information might include the knowledge (in terms of both first-order relational information and structural information; Reed et al., 2006) that the dominant hand of humans is usually placed on their right side, which could explain why face inversion, which disrupts configural processing (Maurer et al., 2002), also disrupts the leftward bias/right-hemispheric dominance in face processing (Ellis and Shepherd, 1975; Leehey et al., 1978; Luh, 1998; Coolican et al., 2008; Anes and Short, 2009; Bourne, 2011). The link between the leftward bias/right-hemispheric dominance and configural processing of faces is further corroborated by their similar developmental trends, configural processing and face-inversion effects also reaching adult-like levels by the age of 10 years (Carey and Diamond, 1977; Diamond and Carey, 1977; Mondloch et al., 2002), as well as by the finding that face-inversion effects appear to be stronger in the left rather than the right visual field (Leehey et al., 1978). In this regard, it is noteworthy that individuals with autism, who exhibit impaired configural processing (Behrmann et al., 2006), are less affected by both the face inversion effect (Hobson et al., 1988; Tantam et al., 1989) and the leftward bias for face processing (Dundas et al., 2012a; Taylor et al., 2012; see also Dundas et al., 2012b).

Another factor reported to affect the leftward bias for faces is maternal preferred cradling side: adults whose mother had an atypical right-side preference for holding infants show a reduced left-bias for chimeric faces compared to adults whose mother had the typical left-side preference (Vervloed et al., 2011). Interestingly, the maternal cradling side is also related to children's handedness, right-cradled infants having slightly higher odds of being lefthanded at 19 months of age (Scola and Vauclair, 2010). Given that children seem to imitate handedness preferences of adults (Harkins and Michel, 1988; Harkins and Uẑgiris, 1991; Michel, 1992; Fagard and Lemoine, 2006), imitation could also account for the greater incidence of left-handedness among right-cradled children, both because left-handed mothers are more likely to cradle on the right side (Scola and Vauclair, 2010) and because holding the infant on one side should free the opposite hand for other tasks (Huheey, 1977; see Hopkins, 2004 for similar associations between cradling side and hand preferences of both mother and infant in nonhuman primates). However, a reduced attentional bias toward the right arm might also explain the smaller leftward bias for faces observed in left-handers and in right-cradled individuals. This hypothesis deserves particular attention, above all in the light of the fact that individuals with autism, who show deficits in action imitation (see Williams et al., 2004 for a review), also exhibit a reduced leftward bias for face processing (Dundas et al., 2012a; Taylor et al., 2012; see also Dundas et al., 2012b) and a higher proportion of non-right-handedness (e.g., Escalante-Mead et al., 2003), which seems not to be accounted for by parental handedness (Tsai, 1982).

\section{SPECIFITY vs. GENERALIZABILITY OF LEFTWARD BIASES}

Some evidence indicates that adult humans exhibit a leftward bias for upright human faces, but not for several other classes of stimuli such as vases, landscapes, and fractals (Mertens et al., 1993; Leonards and Scott-Samuel, 2005). Leonards and Scott-Samuel (2005) proposed that the leftward bias might be specific to socially relevant stimuli, and this could be in line with studies suggesting that the more the emotional load of the stimuli or tasks, the greater the leftward bias for faces (Gallois et al., 1989; Coolican et al., 2008; Thompson et al., 2009). In line with this proposal, centrally presented gaze cues (i.e., social stimuli) facilitate the detection of spatially congruent targets presented in the left visual field (that is, the region of the observed person's right hand during a face-toface interaction) but not in the right visual field, whereas arrow cues (i.e., non-social stimuli) are effective for targets presented in both visual fields (Marotta et al., 2012; see also Greene and Zaidel, 2011).

The role of social relevance in the emergence of attentional asymmetries in favor of the left visual field is corroborated by a series of studies by Mogg and Bradley (1999, 2002) showing that threatening faces induced a greater attentional capture compared 
to happy and neutral faces when the faces were subliminally presented in the left but not in the right visual field, and that this effect was particularly apparent for more anxious individuals. A study by Field (2006) found a similar pattern of results, extending the leftward bias for threatening stimuli to a different population (children aged 7-9 years) and different stimuli (animals). Therefore, although the leftward bias/right hemispheric advantage could be more evident for faces, it is not exclusive of this class of stimuli, as also shown by studies generalizing the left visual field bias to photographs of houses and cars (Levine et al., 1984) and line drawings of common objects (Kim et al., 1990). Nonetheless, it is not unreasonable to hypothesize that more general attentional and perceptual asymmetries may arise from an initial leftward bias for faces and/or bodies. Specifically, given that human bodies and faces are the most ecologically relevant and likely the most recurrent stimuli people deal with in everyday life, the asymmetrical processing they elicit could generalize to some extent to other domains. This view would be consistent with the observation that handedness and sex seem to affect the left side bias for faces and other leftward asymmetries in similar ways: according to a meta-analysis of line bisection studies conducted by Jewell and McCourt (2000), in fact, males show a slightly larger pseudoneglect compared to females and right-handers show a slightly larger pseudoneglect compared to left-handers. Interestingly, this latter finding cannot be attributed to the mere use of the left hand, because the authors also mentioned a relative bias in the direction of the hand used to perform bisection, which is consistent with the activation-orientation theory of Kinsbourne (1970). On the contrary, the modulation of pseudoneglect by handedness could match the way in which one's own motor representations seem to affect attentional asymmetries toward humans bodies observed from the front (e.g., Gardner and Potts, 2010; Marzoli et al., 2011a). Finally, the fact that pseudoneglect shows a developmental trend similar to that of the leftward bias for faces also suggests their related origin (Bradshaw et al., 1988; Dellatolas et al., 1996; Failla et al., 2003). However, it should be noted that a left-sided visuospatial bias has also been found in birds (Diekamp et al., 2005), and embryonic light stimulation has been invoked for its emergence (Chiandetti, 2011), which suggests that pseudoneglect could arise from causes other than the social ones.

\section{EMOTIONAL ASYMMETRIES}

On the basis of the literature reviewed in the previous section, social stimuli, and emotional stimuli in particular, are more likely to induce attentional and perceptual asymmetries compared to non social stimuli. In this section, we attempt to conciliate the larger asymmetries observed for emotional stimuli with our main hypothesis. As recently stressed by Watling et al. (2012), future research should address the advantages of lateralization for emotion processing, as well as related gender differences. In this regard, a positive correlation has been observed between children's left hemispatial advantage for emotion perception and their ability to understand emotional states in cartoon situations and in eyes (Workman etal., 2006), as well as in faces, although this was shown only in male children (Watling and Bourne, 2013). However, a recent study extended the positive correlation between left-lateralized processing and performance to the discrimination of both human and chimpanzee faces in both species (Dahl et al., 2013). These studies suggest a link between the lateralization of emotional processing and the understanding of others' emotional/cognitive states, which is bolstered by their similar time course, theory of mind emerging by the age of 4 years and improving during childhood (Baron-Cohen, 1995). Moreover, the leftward bias for faces approaches adult-like levels by the age of 10 years (Chiang et al., 2000; Workman et al., 2006; Anes and Short, 2009; Taylor et al., 2012), just before children start to exhibit a preference for the left eye (from the observer's viewpoint) during face scanning (Birmingham et al., 2012) and a patent improvement in their ability to interpret emotion from eyes (Tonks et al., 2007).

Therefore, one could wonder whether the advantage of the right-hemispheric specialization for emotion processing might lie in monitoring other's emotional states and their subsequent actions within the same hemisphere, and whether leftward biases could be strengthened by the fact that interaction partners' facial expressions and eye movements are constantly associated with their right-handed actions. This hypothesis deserves particular consideration, given that the leftward bias for emotion processing could appear counterintuitive, emotions being expressed more intensely on the left side of the face, which falls in the right visual field of the observer in a face-to-face interaction (Sackeim and Gur, 1978). On the other hand, there is some evidence that anger might be expressed more intensely on the right side of the face (Indersmitten and Gur, 2003) and that the leftward bias might be larger for anti-social emotions (and in particular for anger) than for pro-social emotions (Workman et al., 2000). Thus, the leftward bias appears to be less counterintuitive if one assumes that both bearing a particular sensitivity to the hemiface expressing more intense threat-related facial displays and directing attention toward the region containing the right arm of an angry individual could provide important ecological advantages. This could be particularly true during interactions among males, and we would like to point out that the leftward bias has been reported to be stronger in males than in females (Bourne, 2008; see also Godard and Fiori, 2010). Moreover, in males the leftward bias reaches its highest degree when they observe male faces expressing anger rather than male faces expressing the other five basic emotions or female faces expressing all basic emotions (Rahman and Anchassi, 2012). The uniqueness of anger among emotions has already been proposed by Indersmitten and Gur (2003; see Workman et al., 2000 for similar considerations), who stressed both its nature of evolutionarily important sign for action (its purpose is to prepare the organism for conflict) and its increased likelihood to be appreciated by the perceiver (its greater intensity on the right rather than the left hemiface enhances its impact on the hemisphere more dominant in emotion processing). In the same vein, it is not surprising that more anxious individuals exhibit a greater leftward bias compared to less anxious ones (Heller et al., 1995; Keller et al., 2000; Voelz et al., 2001; Bourne and Vladeanu, 2011), and therefore an interesting experimental question is whether the former also show greater attention toward the right limbs of human bodies compared to the latter.

We would like to remark that the advantages of lateralization for emotion processing discussed in this section are in agreement 
with previous suggestions (e.g., Vallortigara and Rogers, 2005) that (i) the lateralization of cerebral functions enhances cognitive capacity and efficiency (a positive correlation existing between the leftward bias for emotion perception and performance in emotion discrimination), and (ii) the alignment of the direction of behavioral asymmetries at the population level emerges, as an evolutionary stable strategy, under social pressures (the leftward bias for emotion processing being credited to the advantage of monitoring others' emotional states and their dominant hand within the same hemisphere).

\section{COUPLING BETWEEN FACE AND BODY PROCESSING}

Our proposal that the leftward bias for faces might be associated with a similar bias for bodies is supported by several analogies between face and body processing, including the importance of configural information, the inversion effect affecting both categories (e.g., Reed et al., 2003), and embodied experience, humans being able to move both faces and bodies (Slaughter et al., 2004). On the other hand, face and body representations are likely to differ at least to some extent (e.g., Soria Bauser et al., 2011). Moreover, although both face and body processing develop early in infancy, there is some evidence that face expertise may precede body expertise (Heron-Delaney et al., 2011; Slaughter et al., 2002). A possible account for such a differential development is that the earliest social experiences between infants and caregivers involve a face to face interaction, so that infants are exposed more often to faces than to whole bodies. Surely, face and body representations interact reciprocally (van de Riet and de Gelder, 2008; Yovel et al., 2010; Aviezer et al., 2012) and also induce similar responses (Tamietto et al., 2009).

At the neural level, the same area, the right fusiform gyrus, contains representations for both faces (Kanwisher et al., 1997) and bodies (Peelen and Downing, 2005). Although largely overlapping (Peelen and Downing, 2005), the fusiform face and body areas (FFA, FBA) turned out not to be identical (Schwarzlose et al., 2005; Peelen et al., 2006). Given that the magnitude of the asymmetry of the FFA strongly correlates with leftward asymmetries in face perception (Yovel et al., 2008), the existence of a similar association between FBA and perceptual and attentional asymmetries toward the right side of human bodies deserves investigation. Moreover, whereas the size and selectivity of the rFFA increase with age (Aylward et al., 2005; Golarai et al., 2007; Scherf et al., 2007; Peelen et al., 2009), matching the developmental trend of face-related configural processing and leftward bias, those of the rFBA do not differ between children and adults, this region not showing any development beyond the age of 7 years (Peelen et al., 2009). Thus, given that the age-related increase of the leftward bias for faces can be explained also in terms of the mere maturation of the biological substrate, it could be investigated whether an age-dependent increase in the attention allocated to the right side of human bodies exists and, if so, whether it pre-exists that observed for faces. According to Peelen et al. (2009), a possible account for the differential development of rFFA and rFBA is that young children, when not looking up, usually observe the bodies rather than the faces of older (and thus taller) individuals, whereas adults are more likely to observe the faces of other individuals. For the same reason, the dominant hand might be associated earlier to the right side of bodies rather than of faces, which could contribute to explain why the rFBA reaches adult size before the rFFA. The FFA is also more right-lateralized in right-handers than in left-handers (Willems et al., 2010), in line with the weaker left face bias observed in left-handers. Although less consistent, similar effects of handedness have been reported for the FBA (Willems et al., 2010), which could be linked to the weaker bias toward the right side of bodies observed in left-handers (Gardner and Potts, 2010; Marzoli et al., 2011a,b, 2013).

\section{CONCLUSION AND FUTURE DIRECTIONS}

Although different adaptive reasons have been proposed for the evolution of human right-handedness (Cochet and Byrne, 2013), the adaptive functions of the left face bias, as well as, broadly speaking, perceptual, and attentional asymmetries, have not received the same consideration. The present article attempts to provide a contribution in this direction, suggesting several research questions. The first prediction derived from our hypothesis is that the intensities of the leftward bias for faces and for bodies should be correlated. The leftward bias for bodies could also be modulated by the same factors affecting the leftward bias for faces, such as maternal cradling preference, age, anxiety, emotional context (for example, the presentation of angry faces or voices should increase the bias), configural processing (the bias should be reduced by inversion), and so on.

Moreover, a major topic of investigation should be the effect of experience with right-handed individuals in inducing leftward biases (for both faces and bodies). For example, it could be expected that the bias would be stronger for faces and bodies of highly familiar right-handed individuals than for faces and bodies of unfamiliar individuals. In the same respect, the discovery that dogs show a selective left face bias for human faces (Guo et al., 2009) offers an interesting opportunity to investigate the role of experience also in a nonhuman species. Specifically, it could be tested whether the bias is weakened, or even reversed, in dogs that have interacted mainly with left-handed individuals (i.e., owners, breeders, trainers). Such a study would provide useful information on the contribution of sensory experience in the manifestation and perhaps even in the origin of a perceptual asymmetry whose existence is known since several decades in human beings, but that has recently been observed also in other species.

Finally, an important field of study could address the topic of leftward biases in individuals with autism, who exhibit deficits in social communication (Klin et al., 2003) and emotion recognition from both faces and bodies (Philip et al., 2010), as well as in inferring others' complex mental states from faces and particularly by eyes (Baron-Cohen et al., 1997). These individuals are known to show impaired configural processing (Behrmann et al., 2006) and an absent (Dundas et al., 2012a) - or at least delayed (Taylor et al., 2012) - perceptual bias for the left side of faces. Given the link between face and body representations, it should be investigated whether in this population the reduced leftward bias for faces is coupled with a reduced leftward bias for bodies, just as a reduced face-inversion effect (Hobson et al., 1988; Tantam et al., 1989) is coupled with a reduced body inversion effect (Reed et al., 2007). Moreover, it would be interesting to examine whether 
action imitation deficits of individual with autism are positively related to non-right-handedness and negatively related to leftward biases toward faces and bodies. If so, a reduced attention toward the right side of human bodies could be responsible for the abnormal pattern of behavioral asymmetries in the autistic disorder, endorsing once again the role of body representations in social cognition.

\section{REFERENCES}

Aljuhanay, A., Milne, E., Burt, D. M., and Pascalis, O. (2010). Asymmetry in face processing during childhood measured with chimeric faces. Laterality 15, 439 450. doi: 10.1080/13576500902972823

Anes, M. D., and Short, L. A. (2009). Adult-like competence in perceptual encoding of facial configuration by the right hemisphere emerges after 10 years of age. Perception 38, 333-342. doi: 10.1068/p6092

Aviezer, H., Trope, Y., and Todorov, A. (2012). Holistic person processing: faces with bodies tell the whole story. J. Pers. Soc. Psychol. 103, 20-37. doi: 10.1037/a0027411

Aylward, E. H., Park, J. E., Field, K. M., Parsons, A. C., Richards, T. L., Cramer, S. C., et al. (2005). Brain activation during face perception: evidence of a developmental change. J. Cogn. Neurosci. 17, 308-319. doi: 10.1162/0898929053124884

Balas, B., and Moulson, M. C. (2011). Developing a side bias for conspecific faces during childhood. Dev. Psychol. 47, 1472-1478. doi: 10.1037/a0024494

Baron-Cohen, S. (1995). Mindblindness: An Essay on Autism and Theory of Mind. Cambridge, MA: MIT Press.

Baron-Cohen, S., Wheelwright, S., and Joliffe, T. (1997). Is there a "language of the eyes?" Evidence from normal adults, and adults with autism or Asperger syndrome. Vis. Cogn. 4, 311-331. doi: 10.1080/713756761

Behrmann, M., Avidan, G., Leonard, G. L., Kimchi, R., Luna, B., Humphreys, K., et al. (2006). Configural processing in autism and its relationship to face processing. Neuropsychologia 44, 110-129. doi: 10.1016/j.neuropsychologia.2005.04.002

Bentin, S., Allison, T., Puce, A., Perez, E., and McCarthy, G. (1996). Electrophysiological studies of face perception in humans. J. Cogn. Neurosci. 8, 551-565. doi: 10.1162/jocn.1996.8.6.551

Birmingham, E., Meixner, T., Iarocci, G., Kanan, C., Smilek, D., and Tanaka, J. W. (2012). The moving window technique: a window into developmental changes in attention during facial emotion recognition. Child Dev. 84, 1407-1424. doi: 10.1111/cdev.12039

Bourne, V. J. (2008). Examining the relationship between degree of handedness and degree of cerebral lateralization for processing facial emotion. Neuropsychology 22, 350-356. doi: 10.1037/0894-4105.22.3.350

Bourne, V. J. (2011). Examining the effects of inversion on lateralisation for processing facial emotion. Cortex 47, 690-695. doi: 10.1016/j.cortex.2010.04.003

Bourne, V. J., and Vladeanu, M. (2011). Lateralisation for processing facial emotion and anxiety: contrasting state, trait and social anxiety. Neuropsychologia 49, 1343 1349. doi: 10.1016/j.neuropsychologia.2011.02.008

Bowers, D., and Heilman, K. M. (1980). Pseudoneglect: effects of hemispace on a tactile line bisection task. Neuropsychologia 18, 491-498. doi: 10.1016/00283932(80)90151-7

Bradshaw, J. L., Spataro, J. A., Harris, M., Nettleton, N. C., and Bradshaw, J. (1988). Crossing the midline by four to eight year old children. Neuropsychologia 26, 221-235. doi: 10.1016/0028-3932(88)90076-0

Brancucci, A., Lucci, G., Mazzatenta, A., and Tommasi, L. (2009). Asymmetries of the human social brain in the visual, auditory and chemical modalities. Philos. Trans. R. Soc. Lond. B Biol. Sci. 364, 895-914. doi: 10.1098/rstb.2008.0279

Brodie, E. E., and Dunn, E. M. (2005). Visual line bisection in sinistrals and dextrals as a function of hemispace, hand, and scan direction. Brain Cogn. 58, 149-156. doi: 10.1016/j.bandc.2004.09.019

Bryden, M. P. (1973). Perceptual asymmetry in vision: relation to handedness, eyedness, and speech lateralization. Cortex 9, 419-435. doi: 10.1016/S00109452(73)80041-3

Burt, D. M., and Perrett, D. I. (1997). Perceptual asymmetries in judgements of facial attractiveness, age, gender, speech and expression. Neuropsychologia 35, 685-693. doi: 10.1016/S0028-3932(96)00111-X

Butler, S., Gilchrist, I. D., Burt, D. M., Perrett, D. I., Jones, E., and Harvey, M. (2005). Are the perceptual biases found in chimeric face processing reflected in eye-movement patterns? Neuropsychologia 43, 52-59. doi: 10.1016/j.neuropsychologia.2004.06.005
Carey, S., and Diamond, R. (1977). From piecemeal to configurational representation of faces. Science 195, 312-314. doi: 10.1126/science.831281

Chiandetti, C. (2011). Pseudoneglect and embryonic light stimulation in the avian brain. Behav. Neurosci. 125, 775-782. doi: 10.1037/a0024721

Chiang, C. H., Ballantyne, A. O., and Trauner, D. A. (2000). Development of perceptual asymmetry for free viewing of chimeric stimuli. Brain Cogn. 44, 415-424. doi: 10.1006/brcg.1999.1202

Cochet, H., and Byrne, R. W. (2013). Evolutionary origins of human handedness: evaluating contrasting hypotheses. Anim. Cogn. 16, 531-542. doi: 10.1007/s10071-013-0626-y

Coolican, J., Eskes, G. A., McMullen, P. A., and Lecky, E. (2008). Perceptual biases in processing facial identity and emotion. Brain Cogn. 66, 176-187. doi: 10.1016/j.bandc.2007.07.001

Corbetta, M., and Shulman, G. L. (2002). Control of goal-directed and stimulusdriven attention in the brain. Nat. Rev. Neurosci. 3, 201-215. doi: 10.1038/nrn755

Coren, S., and Porac, C. (1977). Fifty centuries of right-handedness: the historical record. Science 198, 631-632. doi: 10.1126/science.335510

Dahl, C. D., Rasch, M. J., Tomonaga, M., and Adachi, I. (2013). Laterality effect for faces in chimpanzees (Pan troglodytes). J. Neurosci. 33, 13344-13349. doi: 10.1523/JNEUROSCI.0590-13.2013

Dalby, J. T., Gibson, D., Grossi, V., and Schneider, R. D. (1980). Lateralized hand gesture during speech. J. Mot. Behav. 12, 292-297. doi: 10.1080/00222895.1980.10735228

Dellatolas, G., Coutin, T., and De Agostini, M. (1996). Bisection and perception of horizontal lines in normal children. Cortex 32, 705-715. doi: 10.1016/S00109452(96)80040-2

Diamond, R., and Carey, S. (1977). Developmental changes in the representation of faces. J. Exp. Child Psychol. 23, 1-22. doi: 10.1016/0022-0965(77)90069-8

Diekamp, B., Regolin, L., Güntürkün, O., and Vallortigara, G. (2005). A left-sided visuospatial bias in birds. Curr. Biol. 15, R372-R373. doi: 10.1016/j.cub.2005.05.017

Dundas, E. M., Best, C. A., Minshew, N. J., and Strauss, M. S. (2012a). A lack of left visual field bias when individuals with autism process faces. J. Autism Dev. Disord. 42, 1104-1111. doi: 10.1007/s10803-011-1354-2

Dundas, E., Gastgeb, H., and Strauss, M. S. (2012b). Left visual field biases when infants process faces: a comparison of infants at high-and low-risk for autism spectrum disorder. J. Autism. Dev. Disord. 42, 2659-2668. doi: 10.1007/s10803012-1523-y

Ellis, H. D., and Shepherd, J. W. (1975). Recognition of upright and inverted faces presented in the left and right visual fields. Cortex 11, 3-7. doi: 10.1016/S00109452(75)80014-1

Escalante-Mead, P. R., Minshew, N. J., and Sweeney, J. A. (2003). Abnormal brain lateralization in high-functioning autism. J. Autism. Dev. Disord. 33, 539-543. doi: 10.1023/A:1025887713788

Fagard, J., and Lemoine, C. (2006). The role of imitation in the stabilization of handedness during infancy. J. Integr. Neurosci. 5, 519-533. doi: $10.1142 / \mathrm{S} 0219635206001343$

Failla, C. V., Sheppard, D. M., and Bradshaw, J. L. (2003). Age and responding-hand related changes in performance of neurologically normal subjects on the linebisection and chimeric-faces tasks. Brain Cogn. 52, 353-363. doi: 10.1016/S02782626(03)00181-7

Field, A. P. (2006). Watch out for the beast: fear information and attentional bias in children. J. Clin. Child Adolesc. Psychol. 35, 431-439. doi: 10.1207/s15374424jccp3503_8

Gardner, M. R., and Potts, R. (2010). Hand dominance influences the processing of observed bodies. Brain Cogn. 73, 35-40. doi: 10.1016/j.bandc.2010.02.002

Gallois, P., Buquet, C., Charlier, J., Paris, V., Hache, J. C., and Dereux, J. F. (1989). Asymetrie dans l'activité perceptive visuelle des visages et des expressions faciales emotionnelles. Rev. Neurol. 145, 661-664.

Godard, O., and Fiori, N. (2010). Sex differences in face processing: are women less lateralized and faster than men? Brain Cogn. 73, 167-175. doi: 10.1016/j.bandc.2010.04.008

Golarai, G., Ghahremani, D. G., Whitfield-Gabrieli, S., Reiss, A., Eberhardt, J. L., Gabrieli, J. D., et al. (2007). Differential development of high-level visual cortex correlates with category-specific recognition memory. Nat. Neurosci. 10, 512-522. doi: $10.1038 / \mathrm{nn} 1865$

Greene, D. J., and Zaidel, E. (2011). Hemispheric differences in attentional orienting by social cues. Neuropsychologia 49, 61-68. doi: 10.1016/j.neuropsychologia.2010.11.007 
Greenough, W. T., Black, J. E., and Wallace, C. S. (1987). Experience and brain development. Child Dev. 58, 539-559. doi: 10.2307/1130197

Guo, K., Meints, K., Hall, C., Hall, S., and Mills, D. (2009). Left gaze bias in humans, rhesus monkeys and domestic dogs. Anim. Cogn. 12, 409-418. doi: 10.1007/s10071-008-0199-3

Hagemann, N. (2009). The advantage of being left-handed in interactive sports. Attent. Percept. Psychophys. 71, 1641-1648. doi: 10.3758/APP.71.7.1641

Harkins, D. A., and Michel, G. F. (1988). Evidence for a maternal effect on infant hand - use preferences. Dev. Psychobiol. 21, 535-541. doi: 10.1002/dev. 420210604

Harkins, D. A., and Uẑgiris, I. Č. (1991). Hand-use matching between mothers and infants during the first year. Infant Behav. Dev. 14, 289-298. doi: 10.1016/01636383(91)90023-L

Heath, R., Rouhana, A., and Abi Ghanem, D. (2005). Asymmetric bias in perception of facial affect among Roman and Arabic script readers. Laterality 10, 51-64. doi: $10.1080 / 13576500342000293$

Heller, W., and Levy, J. (1981). Perception and expression of emotion in righthanders and left-handers. Neuropsychologia 19, 263-272. doi: 10.1016/00283932(81)90110-X

Heller, W., Etienne, M. A., and Miller, G. A. (1995). Patterns of perceptual asymmetry in depression and anxiety: implications for neuropsychological models of emotion and psychopathology. J. Abnorm. Psychol. 104, 327-333. doi: 10.1037/0021-843X.104.2.327

Heron-Delaney, M., Wirth, S., and Pascalis, O. (2011). Infants' knowledge of their own species. Philos. Trans. R. Soc. B Biol. Sci. 366, 1753-1763. doi: 10.1098/rstb.2010.0371

Hobson, R. P., Ouston, J., and Lee, A. (1988). What's in a face? The case of autism. Br. J. Psychol. 79, 441-453. doi: 10.1111/j.2044-8295.1988.tb 02745.x

Hopkins, W. D. (2004). Laterality in maternal cradling and infant positional biases: implications for the development and evolution of hand preferences in nonhuman primates. Int. J. Primatol. 25, 1243-1265. doi: 10.1023/B:IJOP.0000043961.89133.3d

Hopkins, W. D. (2006). Comparative and familial analysis of handedness in great apes. Psychol. Bull. 132, 538-559. doi: 10.1037/0033-2909.132.4.538

Hoptman, M., and Levy, J. (1988). Perceptual asymmetries in left- and right-handers for cartoon and real faces. Brain Cogn. 8, 178-188. doi: 10.1016/02782626(88)90048-6

Hsiao, J. H., and Cottrell, G. (2008). Two fixations suffice in face recognition. Psychol. Sci. 19, 998-1006. doi: 10.1111/j.1467-9280.2008.02191.x

Huheey, J. E. (1977). Concerning the origin of handedness in humans. Behav. Genet. 7, 29-32.

Indersmitten, T., and Gur, R. C. (2003). Emotion processing in chimeric faces: hemispheric asymmetries in expression and recognition of emotions. J. Neurosci. $23,3820-3825$.

Jaynes, J. (1976). The Origin of Consciousness in the Breakdown of the Bicameral Mind. Boston: Houghton Mifflin.

Jewell, G., and McCourt, M. E. (2000). Pseudoneglect: a review and meta-analysis of performance factors in line bisection tasks. Neuropsychologia 38, 93-110. doi: 10.1016/S0028-3932(99)00045-7

Kanwisher, N., McDermott, J., and Chun, M. M. (1997). The fusiform face area: a module in human extrastriate cortex specialized for face perception. J. Neurosci. $17,4302-4311$

Keller, J., Nitschke, J. B., Bhargava, T., Deldin, P. J., Gergen, J. A., Miller, G. A., et al. (2000). Neuropsychological differentiation of depression and anxiety. J. Abnorm Psychol. 109, 3-10. doi: 10.1037/0021-843X.109.1.3

Kim, H., Levine, S. C., and Kertesz, S. (1990). Are variations among subjects in lateral asymmetry real individual differences or random error in measurement? Putting variability in its place. Brain Cogn. 14, 220-242. doi: 10.1016/0278 2626(90)90031-I

Kimura, D. (1973a). Manual activity during speaking - I. Right-handers. Neuropsychologia 11, 45-50. doi: 10.1016/0028-3932(73)90063-8

Kimura, D. (1973b). Manual activity during speaking-II. Left-handers. Neuropsychologia 11, 51-55. doi: 10.1016/0028-3932(73)90064-X

Kinsbourne, M. (1970). The cerebral basis of lateral asymmetries in attention. Acto Psychol. 33, 193-201. doi: 10.1016/0001-6918(70)90132-0

Klin, A., Jones, W., Schultz, R., and Volkmar, F. (2003). The enactive mind, or from actions to cognition: lessons from autism. Philos. Trans. R. Soc. Lond. B Biol. Sci. 358, 345-360. doi: 10.1098/rstb.2002.1202
Kolb, B., Wilson, B., and Taylor, L. (1992). Developmental changes in the recognition and comprehension of facial expression: implications for frontal lobe function. Brain Cogn. 20, 74-84. doi: 10.1016/0278-2626(92)90062-Q

Lavergne, J., and Kimura, D. (1987). Hand movement asymmetry during speech: no effect of speaking topic. Neuropsychologia 25, 689-693. doi: 10.1016/00283932(87)90060-1

Leehey, S., Carey, S., Diamond, R., and Cahn, A. (1978). Upright and inverted faces: the right hemisphere knows the difference. Cortex 14, 411-419. doi: 10.1016/S0010-9452(78)80067-7

Leonards, U., and Scott-Samuel, N. E. (2005). Idiosyncratic initiation of saccadic face exploration in humans. Vision Res. 45, 2677-2684. doi: 10.1016/j.visres.2005.03.009

Levine, S. C., and Levy, J. (1986). Perceptual asymmetry for chimeric faces across the life span. Brain Cogn. 5, 291-306. doi: 10.1016/0278-2626(86)90033-3

Levine, S. C., Banich, M. T., and Koch-Weser, M. (1984). Variations in patterns of lateral asymmetry among dextrals. Brain Cogn. 3, 317-334. doi: 10.1016/02782626(84)90024-1

Lindell, A. K. (2013). Continuities in emotion lateralization in human and nonhuman primates. Front. Hum. Neurosci. 7:464. doi: 10.3389/fnhum.2013.00464

Liu, S., Quinn, P. C., Wheeler, A., Xiao, N., Ge, L., and Lee, K. (2011). Similarity and difference in the processing of same-and other-race faces as revealed by eye tracking in 4-to 9-month-olds. J. Exp. Child Psychol. 108, 180-189. doi: 10.1016/j.jecp.2010.06.008

Luh, K. E. (1998). Effect of inversion on perceptual biases for chimeric faces. Brain Cogn. 37, 105-108.

Luh, K. E., Red, J., and Levy, J. (1994). Left- and right-handers see people differently: free-vision perceptual asymmetries for chimeric stimuli. Brain Cogn. 14, 141-160. doi: 10.1006/brcg.1994.1028

Marotta, A., Lupiáñez, J., and Casagrande, M. (2012). Investigating hemispheric lateralization of reflexive attention to gaze and arrow cues. Brain Cogn. 80, 361366. doi: 10.1016/j.bandc.2012.08.001

Marzoli, D., Menditto, S., Lucafò, C., and Tommasi, L. (2013). Imagining others' handedness: visual and motor processes in the attribution of the dominant hand to an imagined agent. Exp. Brain Res. 22, 37-46. doi: 10.1007/s00221-0133587-0

Marzoli, D., Mitaritonna, A., Moretto, F., Carluccio, P., and Tommasi, L. (2011a). The handedness of imagined bodies in action and the role of perspective taking. Brain Cogn. 75, 51-59. doi: 10.1016/j.bandc.2010.10.002

Marzoli, D., Palumbo, R., Di Domenico, A., Penolazzi, B., Garganese, P., and Tommasi, L. (2011b). The relation between self-reported empathy and motor identification with imagined agents. PLOS ONE 6:e14595. doi: 10.1371/journal.pone.0014595

Maurer, D., Le Grand, R., and Mondloch, C. J. (2002). The many faces of configural processing. Trends Cogn. Sci. 6, 255-260. doi: 10.1016/S1364-6613(02)01903-4

Megreya, A. M., and Havard, C. (2011). Left face matching bias: right hemisphere dominance or scanning habits? Laterality 16, 75-92. doi: 10.1080/13576500903213755

Meguerditchian, A., Vauclair, J., and Hopkins, W. D. (2013). On the origins of human handedness and language: a comparative review of hand preferences for bimanual coordinated actions and gestural communication in nonhuman primates. Dev. Psychobiol. 55, 637-650. doi: 10.1002/dev.21150

Mertens, I., Siegmund, H., and Grüsser, O. J. (1993). Gaze motor asymmetries in the perception of faces during a memory task. Neuropsychologia 31, 989-998. doi: 10.1016/0028-3932(93)90154-R

Mesulam, M. (1981). A cortical network for directed attention and unilateral neglect. Ann. Neurol. 10, 309-325.

Michel, G. F. (1992). Maternal influences on infant hand-use during play with toys. Behav. Genet. 22, 163-176. doi: 10.1007/BF01066995

Mogg, K., and Bradley, B. P. (1999). Orienting of attention to threatening facial expressions presented under conditions of restricted awareness. Cogn. Emot. 13, 713-740. doi: 10.1080/026999399379050

Mogg, K., and Bradley, B. P. (2002). Selective orienting of attention to masked threat faces in social anxiety. Behav. Res. Ther. 40, 1403-1414. doi: 10.1016/S00057967(02)00017-7

Mondloch, C. J., Le Grand, R., and Maurer, D. (2002). Configural face processing develops more slowly than featural face processing. Perception 31, 553-566. doi: $10.1068 / \mathrm{p} 3339$

Peelen, M. V., and Downing, P. E. (2005). Selectivity for the human body in the fusiform gyrus. J. Neurophysiol. 93, 603-608. doi: 10.1152/jn.00513.2004 
Peelen, M. V., Glaser, B., Vuilleumier, P., and Eliez, S. (2009). Differential development of selectivity for faces and bodies in the fusiform gyrus. Dev. Sci. 12, F16-F25. doi: 10.1111/j.1467-7687.2009.00916.x

Peelen, M. V., Wiggett, A. J., and Downing, P. E. (2006). Patterns of fMRI activity dissociate overlapping functional brain areas that respond to biological motion. Neuron 49, 815-822. doi: 10.1016/j.neuron.2006.02.004

Peirce, J. W., Leigh, A. E., and Kendrick, K. M. (2000). Configurational coding, familiarity and the right hemisphere advantage for face recognition in sheep. Neuropsychologia 38, 475-483. doi: 10.1016/S0028-3932(99) 00088-3

Peirce, J. W., Leigh, A. E., daCosta, A. P. C., and Kendrick, K. M. (2001). Human face recognition in sheep: lack of configurational coding and right hemisphere advantage. Behav. Process. 55, 13-26. doi: 10.1016/S0376-6357(01)00158-9

Philip, R. C. M., Whalley, H. C., Stanfield, A. C., Sprengelmeyer, R., Santos, I. M., Young, A. W., et al. (2010). Deficits in facial, body movement and vocal emotional processing in autism spectrum disorders. Psychol. Med. 40, 1919-1929. doi: 10.1017/S0033291709992364

Prete, G., D’Ascenzo, S., Laeng, B., Fabri, M., Foschi, N., and Tommasi, L. (2013). Conscious and unconscious processing of facial expressions: evidence from two split-brain patients. J. Neuropsychol. doi: 10.1111/jnp.12034 [Epub ahead of print].

Racca, A., Guo, K., Meints, K., and Mills, D. S. (2012). Reading faces: differential lateral gaze bias in processing canine and human facial expressions in dogs and 4-year-old children. PLOS ONE 7:e36076. doi: 10.1371/journal.pone. 0036076

Rahman, Q., and Anchassi, T. (2012). Men appear more lateralized when noticing emotion in male faces. Emotion 12, 174-179. doi: 10.1037/a0024416

Raymond, M., Pontier, D., Dufour, A. B., and Moller, A. P. (1996). Frequencydependent maintenance of left handedness in humans. Proc. R. Soc. Lond. B Biol. Sci. 263, 1627-1633. doi: 10.1098/rspb.1996.0238

Reed, C. L., Beall, P. M., Stone, V. E., Kopelioff, L., Pulham, D. J., and Hepburn, S. L. (2007). Brief report: perception of body posture - what individuals with autism spectrum disorder might be missing. J. Autism. Dev. Disord. 37, 1576-1584. doi: 10.1007/s10803-006-0220-0

Reed, C. L., Stone, V. E., Bozova, S., and Tanaka, J. (2003). The body-inversion effect. Psychol. Sci. 14, 302-308. doi: 10.1111/1467-9280.14431

Reed, C. L., Stone, V. E., Grubb, J. D., and McGoldrick, J. E. (2006). Turning configural processing upside down: part and whole body postures. J. Exp. Psychol. Hum. Percept. Perform. 32, 73-87. doi: 10.1037/0096-1523.32.1.73

Reynolds, D. M., and Jeeves, M. A. (1978). A developmental study of hemisphere specialization for recognition of faces in normal subjects. Cortex 14, 511-520. doi: 10.1016/S0010-9452(78)80026-4

Rosa Salva, O., Regolin, L., and Vallortigara, G. (2007). Chicks discriminate human gaze with their right hemisphere. Behav. Brain Res. 177, 15-21. doi: 10.1016/j.bbr.2006.11.020

Roszkowski, M. J., and Snelbecker, G. E. (1982). Validity and temporal stability of the chimeric face technique for studying hemispheric processing asymmetries: data from 6-through 14-year-old children. J. Behav. Assess. 4, 209-221. doi 10.1007/BF01321266

Sackeim, H. A., and Gur, R. C. (1978). Lateral asymmetry in intensity of emotional expression. Neuropsychologia 16, 473-481. doi: 10.1016/0028-3932(78)90070-2

Sakhuja, T., Gupta, G. C., Singh, M., and Vaid, J. (1996). Reading habits affect asymmetries in facial affect judgments: a replication. Brain Cogn. 32, 162-165.

Saucier, D. M., and Elias, L. J. (2001). Lateral and sex differences in manual gesture during conversation. Laterality 6, 239-245. doi: 10.1080/713754416

Scherf, K. S., Behrmann, M., Humphreys, K., and Luna, B. (2007). Visual category-selectivity for faces, places and objects emerges along different developmental trajectories. Dev. Sci. 10, F15-F30. doi: 10.1111/j.1467-7687.2007. 00595.x

Schwarzlose, R. F., Baker, C. I., and Kanwisher, N. (2005). Separate face and body selectivity on the fusiform gyrus. J. Neurosci. 25, 11055-11059. doi: 10.1523/JNEUROSCI.2621-05.2005

Scola, C., and Vauclair, J. (2010). Is infant holding-side bias related to motor asymmetries in mother and child? Dev. Psychobiol. 52, 475-486. doi: 10.1002/dev. 20450

Slaughter, V., Heron, M., and Sim, S. (2002). Development of preferences for the human body shape in infancy. Cognition 85, B71-B81. doi: 10.1016/S00100277(02)00111-7
Slaughter, V., Stone, V. E., and Reed, C. (2004). Perception of faces and bodies similar or different? Curr. Dir. Psychol. Sci. 13, 219-223. doi: 10.1111/j.09637214.2004.00312.x

Soria Bauser, D. A., Suchan, B., and Daum, I. (2011). Differences between perception of human faces and body shapes: evidence from the composite illusion. Vision Res. 51, 195-202. doi: 10.1016/j.visres.2010.11.007

Tamietto, M., Castelli, L., Vighetti, S., Perozzo, P., Geminiani, G., Weiskrantz, L., and de Gelder, B. (2009). Unseen facial and bodily expressions trigger fast emotional reactions. Proc. Natl. Acad. Sci. U.S.A. 106, 17661-17666. doi: 10.1073/pnas.0908994106

Tantam, D., Monaghan, L., Nicholson, H., and Stirling, J. (1989). Autistic children's ability to interpret faces: a research note. J. Child Psychol. Psychiatry 30, 623-630. doi: 10.1111/j.1469-7610.1989.tb00274.x

Taylor, S., Workman, L., and Yeomans, H. (2012). Abnormal patterns of cerebral lateralisation as revealed by the universal chimeric faces task in individuals with autistic disorder. Laterality 17, 428-437. doi: 10.1080/1357650X.2010.521751

Thompson, L. A., Malloy, D. M., and LeBlanc, K. L. (2009). Lateralization of visuospatial attention across face regions varies with emotional prosody. Brain Cogn. 69, 108-115. doi: 10.1016/j.bandc.2008.06.002

Tonks, J., Williams, W. H., Frampton, I., Yates, P., and Slater, A. (2007). Assessing emotion recognition in 9-15-years olds: preliminary analysis of abilities in reading emotion from faces, voices and eyes. Brain Injury 21, 623-629. doi: $10.1080 / 02699050701426865$

Tsai, L. Y. (1982). Brief report: handedness in autistic children and their families. J. Autism. Dev. Disord. 12, 421-423. doi: 10.1007/BF01538328

Vaid, J., and Singh, M. (1989). Asymmetries in the perception of facial affect: is there an influence of reading habits. Neuropsychologia 27, 1277-1287. doi: 10.1016/0028-3932(89)90040-7

Vallortigara, G., and Rogers, L. J. (2005). Survival with an asymmetrical brain: advantages and disadvantages of cerebral lateralization. Behav. Brain Sci. 28, 575-589. doi: 10.1017/S0140525X05000105

van de Riet, W. A., and de Gelder, B. (2008). Watch the face and look at the body! Neth. J. Psychol. 64, 143-151. doi: 10.1007/BF03076417

Vervloed, M. P. J., Hendriks, A. W., and van den Eijnde, E. (2011). The effects of mothers' past infant-holding preferences on their adult children's face processing lateralisation. Brain Cogn. 75, 248-254. doi: 10.1016/j.bandc.2011.01.002

Voelz, Z. R., Gencoz, F., Gencoz, T., Pettit, J. W., Perez, M., and Joiner, T. E. Jr. (2001). Patterns of hemispheric perceptual asymmetries: left hemispatial biases predict changes in anxiety and positive affect in undergraduate women. Emotion 1, 339-347. doi: 10.1037/1528-3542.1.4.339

Watling, D., and Bourne, V. J. (2013). Sex differences in the relationship between children's emotional expression discrimination and their developing hemispheric lateralization. Dev. Neuropsychol. 38, 496-506. doi: 10.1080/87565641.2013. 826660

Watling, D., Workman, L., and Bourne, V. J. (2012). Emotion lateralisation: developments throughout the lifespan. Laterality 17, 389-411. doi: $10.1080 / 1357650 X .2012 .682160$

Westergaard, G. C., and Suomi, S. J. (1996). Hand preference for a bimanual task in tufted capuchins (Cebus apella) and rhesus macaques (Macaca mulatta). J. Comp. Psychol. 110, 406-411. doi: 10.1037/0735-7036.110.4.406

Wheeler, A. (2010). The Emergence of a Left Visual Field Bias in Infants' Processing of Dynamic Faces. Doctoral dissertation, University of Toronto, Toronto.

Willems, R. M., Peelen, M. V., and Hagoort, P. (2010). Cerebral lateralization of faceselective and body-selective visual areas depends on handedness. Cereb. Cortex 20, 1719-1725. doi: 10.1093/cercor/bhp234

Williams, J. H., Whiten, A., and Singh, T. (2004). A systematic review of action imitation in autistic spectrum disorder. J. Autism. Dev. Disord. 34, 285-299. doi: 10.1023/B:JADD.0000029551.56735.3a

Workman, L., Chilvers, L., Yeomans, H., and Taylor, S. (2006). Development of cerebral lateralisation for recognition of emotions in chimeric faces in children aged 5 to 11 . Laterality 11, 493-507. doi: 10.1080/13576500600 724963

Workman, L., Peters, S., and Taylor, S. (2000). Lateralisation of perceptual processing of pro-and anti-social emotions displayed in chimeric faces. Laterality 5, 237-249. doi: $10.1080 / 713754378$

Young, A. W., and Bion, P. J. (1980). Absence of any developmental trend in right hemisphere superiority for face recognition. Cortex 16, 213-221. doi: $10.1016 /$ S0010-9452(80)80057-8 
Young, A. W., and Ellis, H. D. (1976). An experimental investigation of developmental differences in ability to recognize faces presented to the left and right cerebral hemispheres. Neuropsychologia 14, 495-498. doi: 10.1016/0028-3932(76) 90078-6

Yovel, G., Pelc, T., and Lubetzky, I. (2010). It's all in your head: why is the body inversion effect abolished for headless bodies? J. Exp. Psychol. Hum. Percept. Perform. 36, 759-767. doi: 10.1037/a0017451

Yovel, G., Tambini, A., and Brandman, T. (2008). The asymmetry of the fusiform face area is a stable individual characteristic that underlies the left-visual-field superiority for faces. Neuropsychologia 46, 3061-3068. doi: 10.1016/j.neuropsychologia.2008.06.017

Zartor, A. S., Mikheev, M. M., and Afanasiev, S. V. (2010). Lateral peculiarities of the process of mental rotation of the human body scheme. J. Evol. Biochem. Physiol. 46, 292-294. doi: 10.1134/S0022093010 030117
Conflict of Interest Statement: The authors declare that the research was conducted in the absence of any commercial or financial relationships that could be construed as a potential conflict of interest.

Received: 31 December 2013; accepted: 10 February 2014; published online: 28 February 2014.

Citation: Marzoli D, Prete G and Tommasi L (2014) Perceptual asymmetries and handedness: a neglected link?. Front. Psychol. 5:163. doi: 10.3389/fpsyg.2014.00163

This article was submitted to Cognition, a section of the journal Frontiers in Psychology. Copyright (c) 2014 Marzoli, Prete and Tommasi. This is an open-access article distributed under the terms of the Creative Commons Attribution License (CC BY). The use, distribution or reproduction in other forums is permitted, provided the original author(s) or licensor are credited and that the original publication in this journal is cited, in accordance with accepted academic practice. No use, distribution or reproduction is permitted which does not comply with these terms. 